\title{
The Spatial Practice of Migrant Communities in Doha, Qatar: The Case of Najada Zone
}

\author{
Asmaa Saleh AL-Mohannadi ${ }^{1}$, Almaha Ahmad AL-Malki ${ }^{2}$, Raffaello Furlan ${ }^{3 *}$ \\ ${ }^{1}$ Architect, Msc. Urban Design, BArch - Master in Urban Planning and Design (MUPD) - Qatar University (Qatar) \\ College of Engineering, Department of Architecture and Urban Planning, Qatar University Doha, Qatar \\ ${ }^{2}$ Architect, Msc. Urban Design, BArch - Master in Urban Planning and Design (MUPD) - Qatar University (Qatar) \\ College of Engineering, Department of Architecture and Urban Planning, Qatar University Doha, Qatar \\ ${ }^{3}$ Architect, PhD - Griffth University (Australia), BArch, MArch - IUAV (Italy) Assistant Professor, College of Engineering, Department of \\ Architecture and Urban Planning, Qatar University Doha, Qatar
}

*Corresponding author: Raffaello Furlan

\section{Abstract}

This research study aims at tracing the human-behavior relationship between current migrant-residents and the built fabric of Najada zone in Doha. It provides a useful insight into the urban reality of migrant communities in a selected neighborhood and suggests that foreseen plans for urban adaptation and revitalization should be considered in alignment with the ever-changing demographics of a city facing fast urban growth. Through various methodological tools embedded into human-behavior studies that support the analysis of spatial practice of communities such as (i) systematic observation, (ii) contemplating settings and (iii) walking tour assessment, the interaction of Najada's users and the surrounding built environment is traced. The purpose of the research study is to provide the basic foundation of analytical data for urban design schemes that encourages preservation and conservation of neglected old neighborhoods, at national and regional scale.

Keywords: Migrant community, Socio-spatial practice, environment-behavior studies, Doha, Qatar, Najada.

Copyright @ 2019: This is an open-access article distributed under the terms of the Creative Commons Attribution license which permits unrestricted use, distribution, and reproduction in any medium for non-commercial use (NonCommercial, or CC-BY-NC) provided the original author and source are credited.

\section{INTRODUCTION}

The State of Qatar announced its National Development Framework (QNDF 2032) as part of its strategic approach toward fulfilling Qatar National Vision 2030 (QNV 2030). The policies defined by QNDF 2032 encloses the conservation areas policy, aiming at protecting and enhancing the cultural heritage of Qatar through active engagement of private and public stakeholders [4]. Accordingly, the area of Downtown Doha, including the zone of Al Najada, is a priority area in the conservation policy, where preservation of historic character is preferred over 'comprehensive redevelopment' [1-3].

Based on the administrative division of the State of Qatar, the zone of Al Najada is located within the municipality of Doha. It is one of the major remains of the old heart of the city surrounded by (i) the most attractive commercial centre of the Souq Waqif; (ii) the emerging project of Doha Downtown developed by Msheireb Properties; (iii) and Al Asmakh area, which has a similar urban setting of Najada except for its vernacular residential character compared to the mixed use and commercial character of the latter [5-8].

Najada is one of the few zones within Doha that contains a treasurable remain of the old buildings, such as mosques and houses, reflecting the national distinctive architectural style. In addition, the zone is mostly occupied by buildings of early-modern and modern styles specifically introduced to the city in the $1960-1980$ s as a reaction to oil wealth and the development of state infrastructure and basic establishments aided by the government [9-11].

Recently, the condition of the existing traditional buildings requires a thorough act of preservation and restoration, while the decision of demolishing some other units is still doubtable. In this prospect, the condition of old buildings in the zone could be classified based on two qualities, according to a preliminary investigative study conducted by Qatar Museums [12,13]. The qualities are related to the different parts of Najada zone, where the first is related to the situation of buildings mainly houses in the 
northern part, which are found to be restorable and presenting outstanding architectural quality. Meanwhile, the second quality is noticeable in the southern part of Najada, which is explained as follows:

"The southern part of Najada is built up with a more simple type of small lanes and narrow courtyard houses, many of which today are neglected and in bad condition. The areas around the compound are facing new buildings of unknown height and function, so that a restoration and rehabilitation of the historical part would be very difficult [12]".

In addition to its degraded urban situation, Najada is characterized by its challenging social and demographic realities. The zone is recently occupied by migrant communities of different ethnological backgrounds residing in the old houses, which got vacated and emptied from original local inhabitants due to changing housing preferences and upgrading local's living standards [14].

This research study aims at tracing the humanbehaviour relationship between the current residents and the built fabric of the selected exemplar case of Najada zone in the heart of Doha. The investigation leads to important remarks on the (i) functionality of the buildings and the built fabric such as streets, edges and corners; (ii) adaptability of architecture to accommodate socio-cultural changes; (iii) as well as other adaptation and revitalization scenarios that could elevate the current neglected urban condition of Najada. It provides a human-behaviour insight into the urban life of migrant communities' realities in the city of Doha and foreseen plans for urban development considering the ever-changing demographics of an evolving city.

\section{LITERATURE REVIEW About Al Najada Neighbourhood}

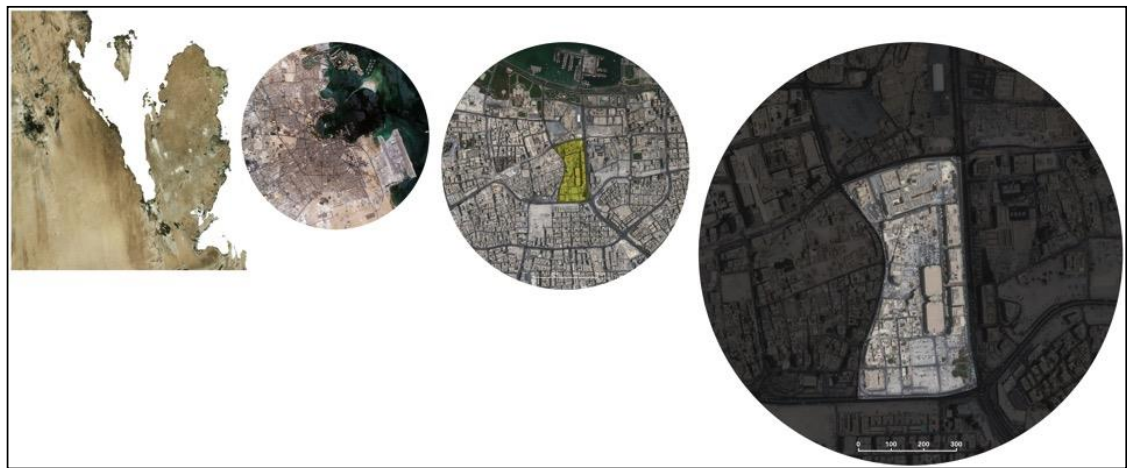

Fig-1: Location of Najada Area (Zone 5) in Doha, Qatar. Source Author's Graphics

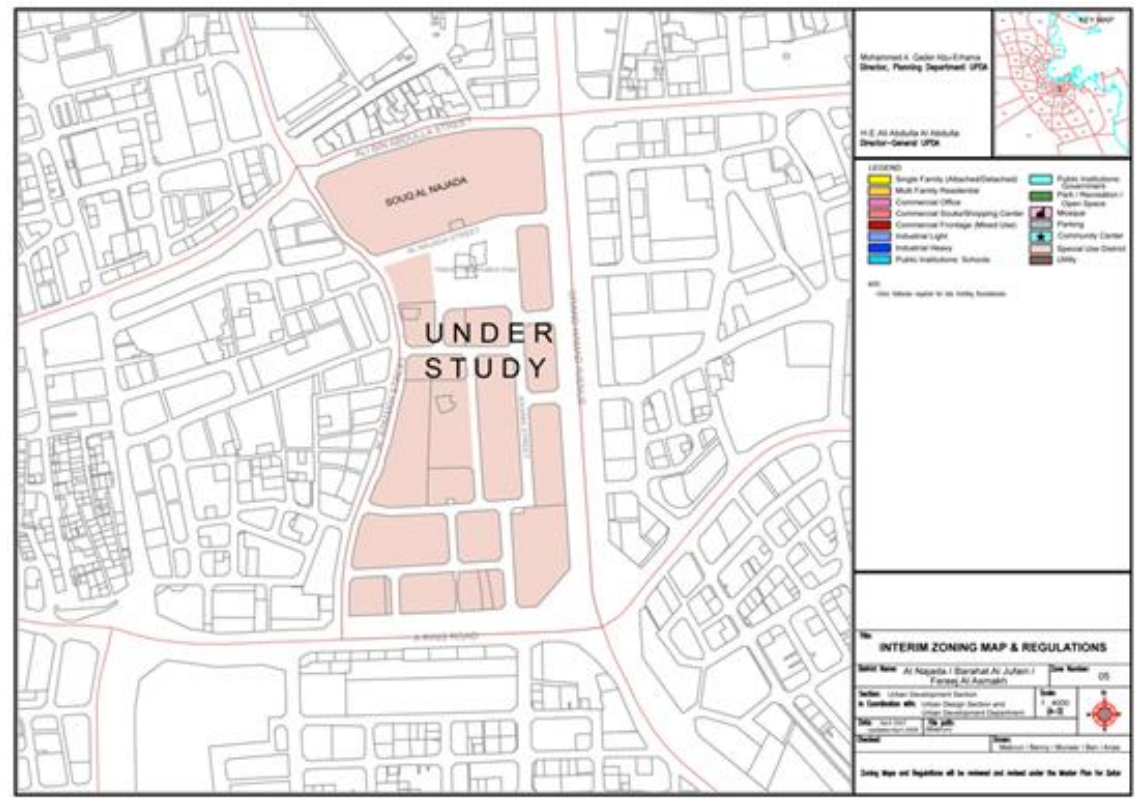

Fig-2: Land Use Zoning of Najada Zone, 2018. Source[15] 


\section{Historical Significance}

In the oldest recorded primary references of Doha's urban fabric such as aerial images and historical maps, the Najada and Al Asmakh areas were partially vacant in 1947 except for a fabric of traditional Qatari mud-houses of a courtyard prototype [5,19, 17,18,19]. In the era of $1950 \mathrm{~s}$, which marks the inauguration of oil wealth into the city making process, the number of buildings increases dramatically in the area, where the boundaries start to appear in the form of main roads separating Najada from neighbouring districts such as Souq Waqif and Msheireb [20-28].

In 1963, the urban fabric of Najada became definable through the continuity of buildings as well as the street networks. The entire area was well developed by the time. Most of the new development was initiated in the southern part of Najada area, where the traditional fabric still existed in its northern part. Later in the 1970s and 1980s, the urban fabric was significantly altered due to demolition of old buildings and construction of street networks. The area has been defined with roundabouts that reflect the increasing dependency on cars and vehicular access, thus decreasing importance of pedestrian capability. In addition, buildings facing the main street started to attract mixed-use functions and transformed into commercial shops and public facilities.
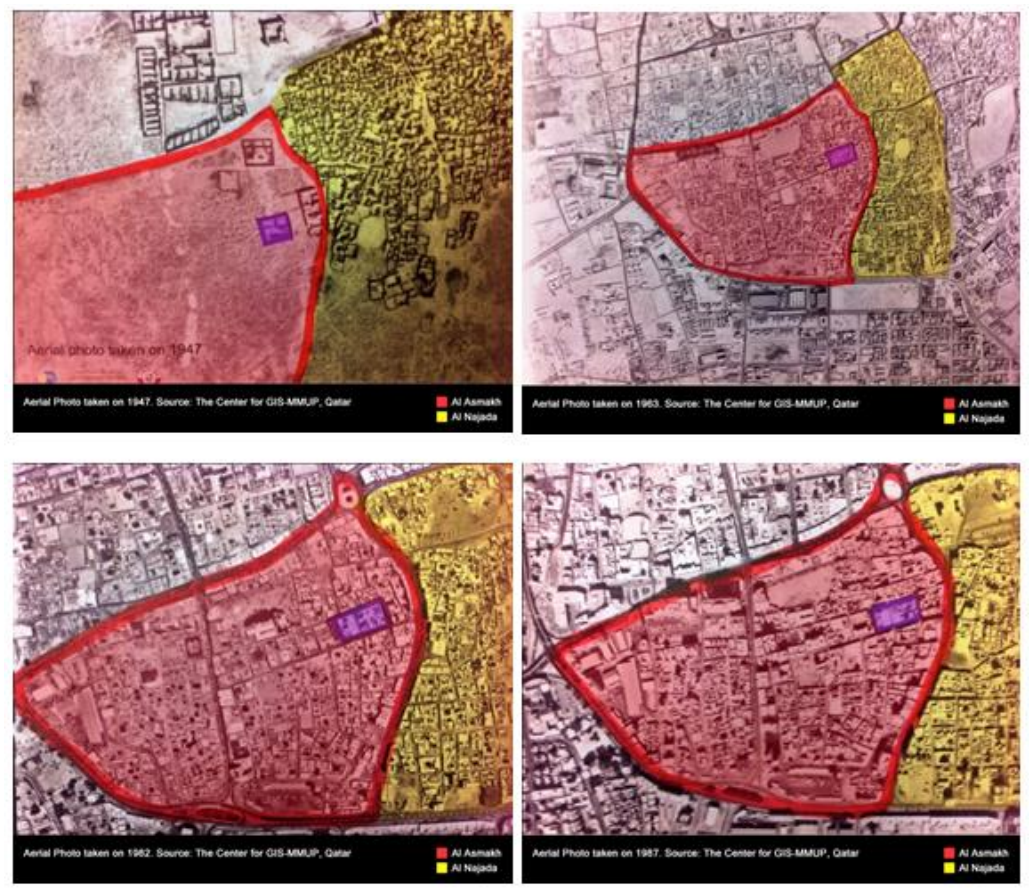

Fig-3: Aerial photos of Najada and Al Asmakh areas from 1947-1987. Source (CGIS-MMUP, 2014). Author's Graphics

\section{Urban Data}

Based on census data, the analysis of Najada's population census reveals that the inhabitants are mainly single men belonging to the migrant working class $[14,29]$. The population density of the zone, measured in kilometre, is relatively high. The building status reflects the inactive construction situation of Najada as well as the urban density in terms of architectural units. However, as a mean of urban growth, few buildings are being demolished.

Fair connection to public facilities is provided in Najada despite being an old zone of Doha. With the limited existence of residential units, most of the facilities serve mosques, commercial quarters and other public facilities. Relating data of building type to housing unit type, the high rank of residential buildings refers to the large number of apartments in the zone, while buildings of a mixed-use character are found rare.

In Najada, housing units are mostly dedicated to serve the current single migrant users of the zone. The most utilized housing alternative in the zone are apartments due to their availability and proximity to main streets. Whereas Arabic houses that might correspond to the traditional courtyard houses still exist in Najada, serving one-third of the total residing population [14. In terms of activity, Najada is an active zone since most of its establishments are in operation due to the commercial nature of the activities taken place within the establishments [14].

\section{Demographic Data}

World widely, Qatar has the highest ratio of migrants to citizens. Among the 1.2 million migrants 
who make up 94\% of Qatar's workforce, workers predominantly coming from India, Nepal, Bangladesh, Sri Lanka and the Philippines, are employed primarily in construction, services, and domestic work [30]. The quarters within which Najada zone exists represent different social groups of the traditional Doha society from merchants to craftsmen. Today, the zone is occupied by migrants belonging to the lower working class and descending from Asian and south-Asian origins, with a stable population growth since 20102014 (Eissa et al., 2015; Salama, Azzali, \& Wiedmann, 2017). Accordingly, "The census studies for 1986, 1997, 2004 and 2010 show that the population density of Al Asmakh, Al Najada and Barahat Al Jufairi increased progressively from 1986 towards 2004, hosting 12,830 inhabitants. However, due to the new urban interventions and urban governance, most of labourers were moved to labour camps located in the city's industrial areas. Consequently, the population of the districts was reduced by one-third in 2010" (Khalfani, 2016).

According to the paradigm of transdisciplinarity, the discipline of ethnology is involved in the process of architectural research to develop a holistic investigation about the spatial organization of the studied zone and its inhabitants. Ethnology is defined as 'the science that analyses and compares human cultures, as in social structure, language, religion and technology' [33]. The diagram below represents the distinctive ethnological background of Najada zone.

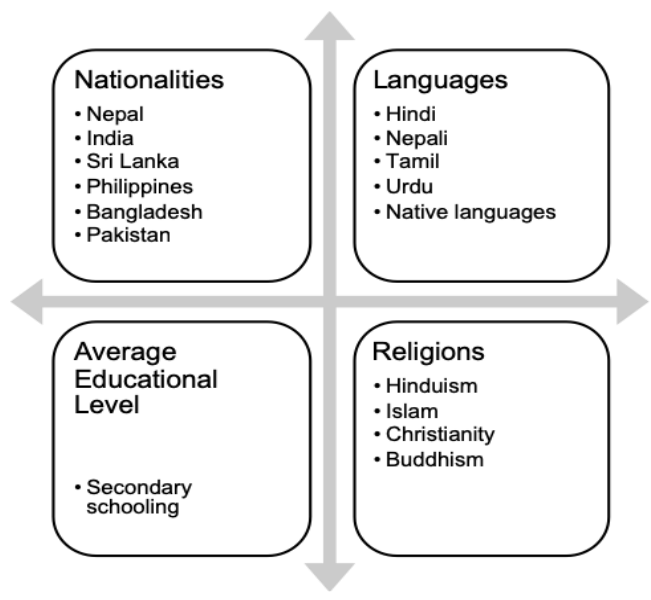

Fig-4: Migrant Labours in Qatar: Demographic Profile. Source Authors' Summary

\section{Analysis of the spatial practice of migrant communities in najada zone}

\section{(a) Cultural Conflict}

Referring to the demographic analysis of Najada zone, the majority of the residents and users are of south-Asian cultural backgrounds. This fact is directly relatable to the socio-behavioral characteristics which shape the way people interact and respond to the surrounding environment. One of the most important concepts is the cultural conflict justifying certain territorial and personalization behaviors perceived in the site of Najada streets and zone.

Generally, culture is understood as a matrix of meanings that plays a constitutive part in generating and preserving a collective identity [16, 2, 10, 34, 35]. In the case of south-Asian cultures, the conflicts between cultures are mostly of domestic nature and within the state. These conflicts are motivated by religious, ethnic and linguistic variations. According to an intensive study on the topic of "Culture, Identity and Conflict in Asia and Southeast Asia" [36], the following statement justifies the nature of domestic cultural conflicts observed in the spatial practice of migrant communities:
" $96 \%$ of cultural conflicts in Southeast Asia take place within states. By contrast, conflicts on cultural issues are rarely fought between states: the proportion of non-cultural conflicts among inter-state conflicts has reached $87 \%$ in South- east Asia. Evidently, regional governments have succeeded in developing mechanisms that prevent existing cultural tensions and conflicts within communities from "spilling over" and thus turning into inter-state conflicts [36]"

Cultural conflict could be considered as a theoretical base in the process of analysing the sociobehavioural phenomena of the users within Najada Street in Doha. As it has been analysed, members of different ethnic groups tend to be interacting with those who are assumingly belonging to their personal or social zone, creating ethnical clusters. Also, behaviours of claiming territoriality are the most perceived acts in the street. The variables by which this argument is based upon are the clothing, positioning in the space, 
Table-1: Cultural Conflict Settings

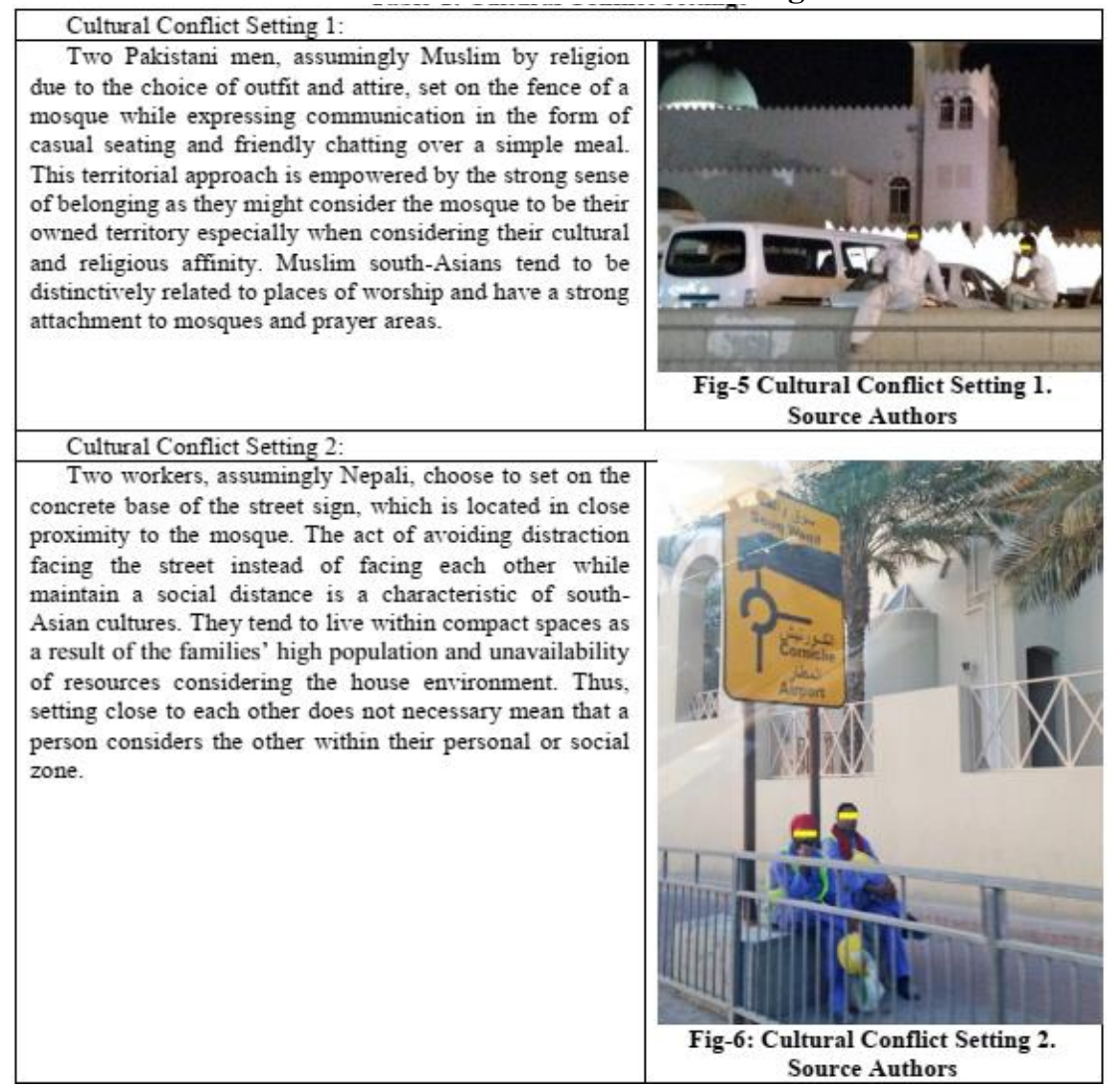

\section{(b) Affordance}

Old appearance and bad conditioning characterize the built environment bordering Najada Street. This fact motivates certain behaviours to appear publicly including throwing wastes on the street; disrespectful acts of polluting the area; and the dependence on cleaning workers to do the cleaning. Moreover, the linear arrangement of the street inspires the creation of traffic chaos thus cars would be spotted parking everywhere. In the case of unavailable parking, cars would stop in the side lane blocking the movement of other users.

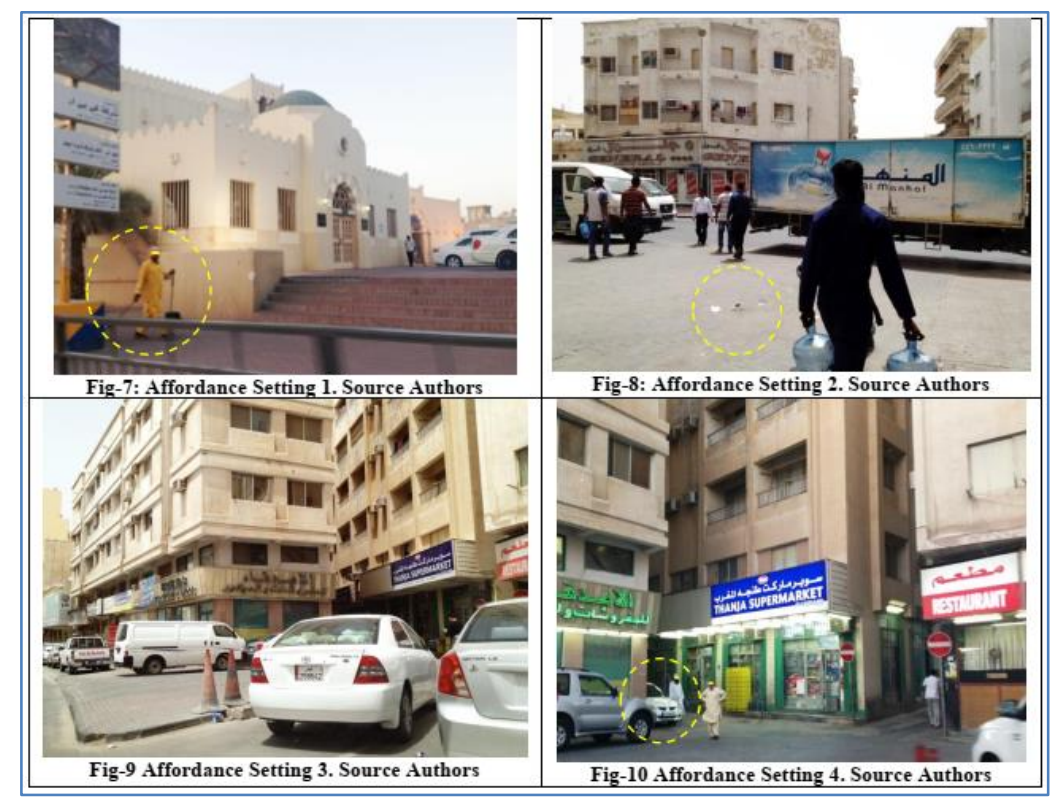




\section{(c) Functional and Behavioural Opportunities}

The absence of public space considerations in terms of design in the site creates fewer opportunities for use manifestation. Therefore, most of the user attributes have different meanings. For instance, the street users tend to set on low-rise fences or concrete boxes as a respondent reaction to the unavailability of seating areas or street furniture. In addition, street signs replace bus stops or shaded waiting areas around which the pedestrian users of the street stand and wait.

\section{(d) Appropriateness and Appropriating}

Considering the demographic background of the street users, many spatial practices reflect a random and un-thoughtful response to the existing conditions. Most of the practices are adapted to their inappropriate use. As it has been analysed, users do not respond to the street signs in terms of their physical and perceptual meanings. Some users would cross the street randomly, not keen to follow the traffic walk-line, which is an act that reflects carelessness or ignorance. Another example is the unmanaged parking areas, where the users continuously break the traffic rules.

\section{(e) Adaptability or Resilience}

The street is generally serving a variety of functions in terms of commercial and residential uses. However, the vertical orientation of the built structures including the medium-rise buildings restricts the public realm from getting expanded. Thus, gathering nods where social interaction takes place are few and architecturally unresponsive.

Cultural interpretations are seen within the residential quarter of Najada, where the urge for housing alternatives forces an act of random adaptation since migrant workers live in traditional Qatari houses and modify spaces to fit their current lifestyle. However, the buildings facing the street maintain their modern and postmodern architectural style reflecting undefined cultural inspiration. Their bad appearance and polluted facades are left unmaintained, suggesting that the residents are either unwilling to change them due to financial reasons, or advocating that current users have no choice but to utilize the buildings albeit their poor condition.

\section{(f) Flexibility}

Acts of prefabrication or redevelopment are possible in the case of Najada zone. Compared to the neighbouring Souq Waqif, however, the existence of early modern and modern buildings does not seem to foster the creation of a traditional district, making Najada less flexible to react to revitalization. Whereas to solve the current urban and demographic chaos, the option would be to relocate the current migrant population to other districts within the country, where the built environment would be flexibility designed to create a dynamic cultural engagement of migrant communities. Such districts would have certain environmental attributes such as crops or farms, where farming-based migrants can satisfy their cultural needs and live in a more satisfactory condition.
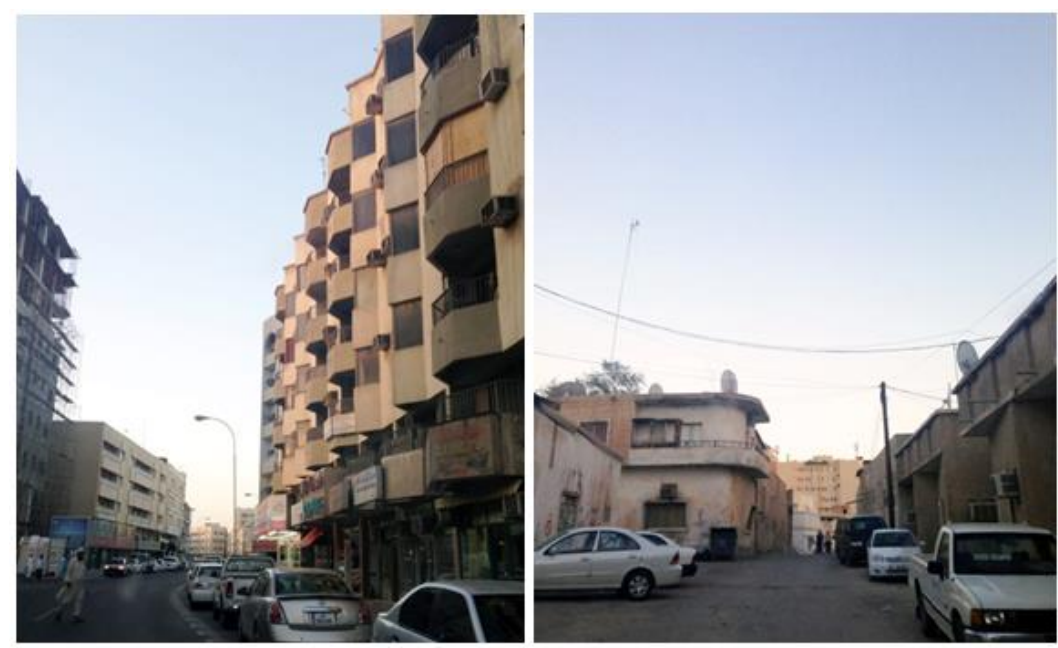

Fig-5: Building situation and style on the street and within the residential area of Najada, Doha. Source Authors

\section{(g) Use Value}

The value of Najada zone is highly associated with its commercial and geographical aspect rather than the socio-cultural or environment-behavioural aspects. The existence of low-class migrant communities makes it less significant in terms of its valuable stand to the whole community of Qatar. Such populations are underestimated and stereotypically portrayed as sources of negative performances. However, migrant communities are unequipped with sufficient means of living that would grant them an equitable access to the society.

A possible justification is related to the strategic plan that regulates the case of migrant communities in Qatar, which is based on temporary 
presence. In order to regain the social value of Najada and its dynamic street, an emphasis should be placed on preparing the public spaces within the zone to respond to territorial behaviours through the design of better street furniture. Urban design should be inclusive and responsive to the demography of the zone in order to widen the socio-cultural effect and create a healthy social hub in the city.

\section{Systematic Observation}
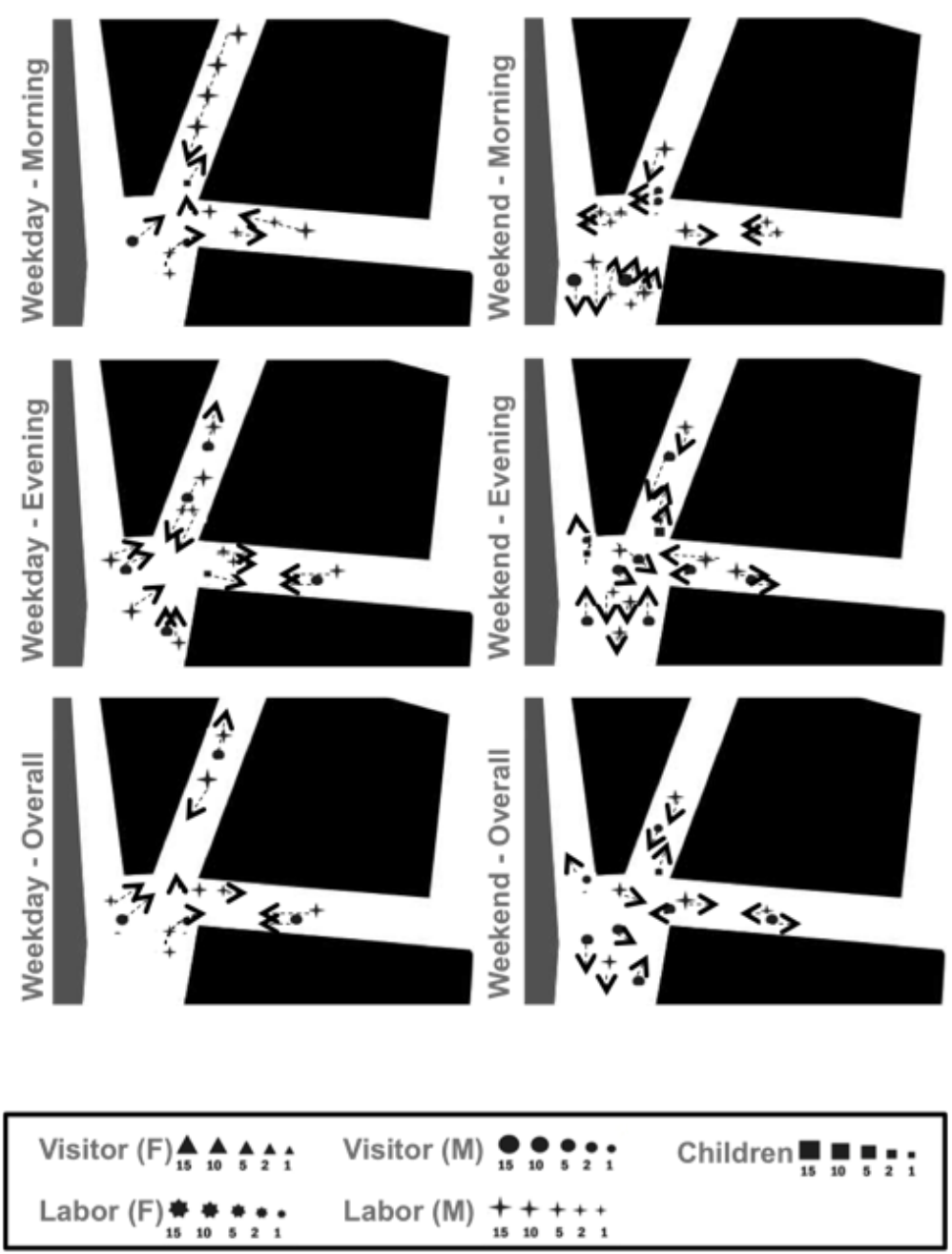

Fig-6: Behavioural Mapping of a Sidewalk Strip, Najada Zone. Source Authors

\section{Weekdays}

- It is observed that during weekdays, the number of pedestrians is less compared to their higher presence during weekends. The number of people increases at the praying times where most of pedestrians are found walking from their houses or shops towards the mosques.

- People usually walk individually with limited interaction. They tend to walk together in groups without talking to each other. Men are the most dominant users of the street. It is rare to find women or families using the amenities on the street or walk as freely as men would do, due to the demography of the site.
- The Najada area houses a number of apartments and hotels where families live, meanwhile the current situation of the street does not support integration of family and children into urban life.

- People tend to socialize near street signs, where they meet and allocate themselves for accessibility. The street lacks open public spaces or plazas that could perform better as nods for meeting and gathering.

\section{Weekends}

- During weekends, it is noticeable that the number of people is approximately three times greater than their number during ordinary weekdays. People come to Najada to meet and interact with each 
other. They gather in any suitable point either next the shop corners or on street edges.

- The situation near the hotels in the streets in the weekends is similar to the weekdays. However, many Arabs and people from neighboring Gulf countries are spotted walking around the hotel, as well as tourists from Europe and American. These people approach to Najada in the weekends to discover the street life and enjoy the architecture style of old Qatar.

- Men are the most dominant users of the street during weekends. However, a number of families are spotted entering furniture shops and general utilities stores.

- Pedestrians who set on the fences increase in the weekends; they tend to create a fence by themselves.

\section{Users and Activities}

The most predominant user of the Najada zone and streets are south-Asian male users, where the presence of women or families is found rare. Table 2 below highlights the statistical data of Najada population per gender.

Table-2: Population per Gender at Najada Area. Source [14]

\begin{tabular}{|l|l|}
\hline Population per Gender & Number \\
\hline Female & 270 \\
\hline Male & 3868 \\
\hline Total per zone & 4138 \\
\hline Total per municipality & $4138 / 1,699,435$ \\
\hline
\end{tabular}

The analysis of Najada's population census suggests that the inhabitants are mainly single men, belonging to the migrant working class. It is understandable from the statistics that the number of men in the zone is 12 times greater than the number of women. In addition, there are different nationalities either living in Najada or using the area mostly from south Asia such as Nepali, Bengali, Indian, Pakistani, Filipino and Korean.

In terms of activities, walking around the Najada street shops and corners is the main activity of the pedestrians and users of the area. Its central location grants a flow of pedestrians all year long and at different time intervals, especially during rush morning and evening hours. However, many pedestrians cross Najada area to meet their fellow workers in shops found in the streets. Such gatherings or meetings occur randomly, usually near the street signs or by shop doors. Pedestrians are found sitting on the steps or on the street grass landscape; using the fences as chairs to sit and talk in absence of street furniture. Other people approach to Najada during work breaks for food due to the high presence of Asian restaurants.

For families, many migrants as well as locals visit Najada area occasionally for shopping purposes, since it is one of the most famous destinations in Doha for furniture and electronic agencies along with lowprice margins and affordable products.

In general, flow of people increases during prayer times around mosques on both edges of the main Najada streets. Considering the huge lack of welldesigned open spaces, shaded areas and public plazas, pedestrians use adaptable techniques to get a way through the harsh weather conditions while enjoying the public life essence of the area.

\section{Walking Assessment}

Functional Aspects

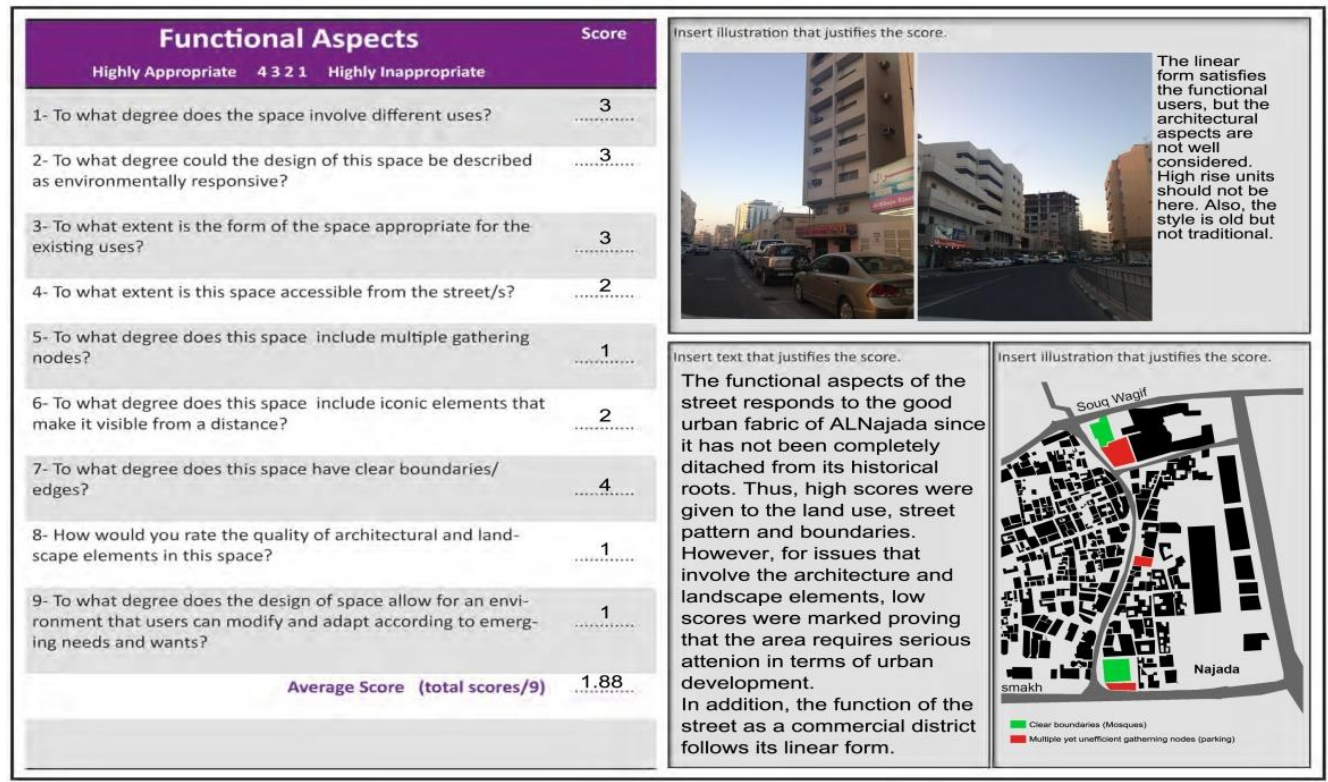

Fig-7: Walking Tour Assessment Tool- Functional Aspects Tool developed by Prof. Salama. Source [32] 
The main street of Najada is a setting for various land uses ranging from residential, commercial to religious and public uses. The area itself is small in size with dense population of immigrant male workers, thus a variety of uses and functions are exhibited in the area. Environmental considerations to the area are minimal; protection against the harsh weather condition is limited to shaded shop entries and canopies of existing buildings while the walkways are kept exposed. The area is accessible and reachable due to its linear urban form as well as close proximity to Souq Waqif. One of the main characteristics of the Najada street architecture is the medium-to-low rise small clusters of old and similar looking buildings. The building envelope does not give a clear indication of the building users or an insight into the functional aspect of the buildings. The narrow corners in the sidewalk strip serve as gathering nodes and meeting points for users due to the absence of specific designated points for meeting or gathering with public space considerations.

\section{Social Aspects}

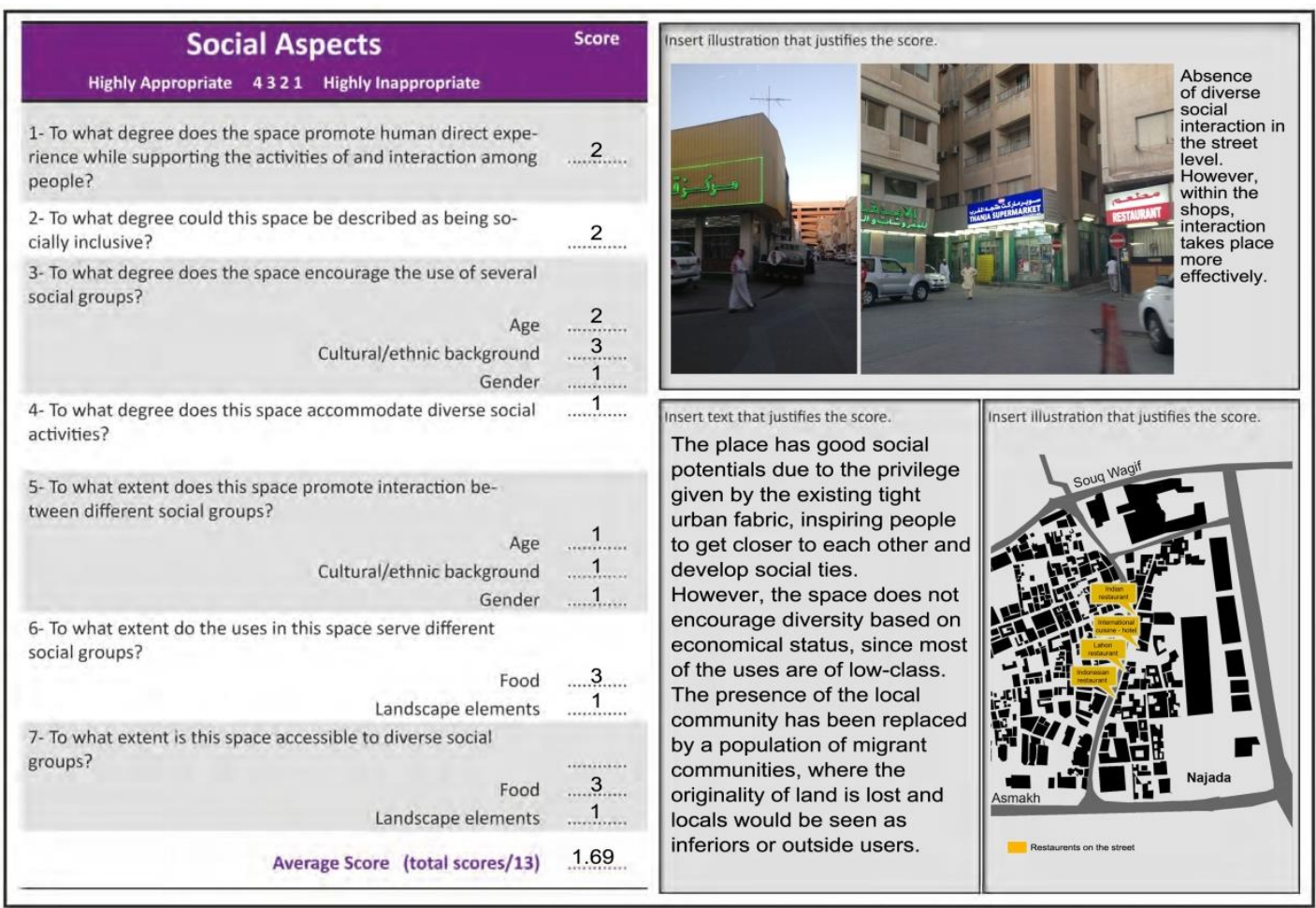

Fig-8: Walking Tour Assessment Tool- Social Aspects. Tool developed by Prof. Salama. Source[32]

The social group of users in the street compromises of multiple ethnicities from South-Asian countries. There is a noticeable active social interaction going on in Najada, however the street furniture does not seem to accommodate the activities taking place in the area. The major environment-behavioral remark is that users tend to adopt functional requirements to forms that are not designed to fit expected needs. For instance, many users are seen sitting in the street edges, fences, and steps or found standing under shades or near a tree.

On the other hand, the area is male dominated, thus low score are given to the assessment the area's gender specifications. Meanwhile, socio-culturally, the area is highly encouraging vibrant cultural and social interactions. In advertisement leaflets attached on the walls throughout the site, different languages are used. The restaurants available are catering to different tastes; there are Indian, Chinese and Indonesian restaurants.

The few spaces dedicated for landscape in the site are poorly designed and insufficient considering the large flow of users. There are no bicycle lanes or proper pedestrian walkways although many users are using bikes as a mean of transportation to avoid the chaotic and crowded car lanes. 


\section{Perceptual Aspects}

\begin{tabular}{|c|c|c|c|}
\hline Perceptual Aspects & Score & \multicolumn{2}{|l|}{ Insert illustration that justifies the score. } \\
\hline Highly Appropriate 4321 Highly Inappropriate & & \multirow{5}{*}{ Le a } & \multirow{3}{*}{$\begin{array}{l}\text { The boundaries } \\
\text { of the street } \\
\text { provides the most } \\
\text { favourable nods of } \\
\text { gatherings for } \\
\text { socializing purposes. } \\
\text { Notice the street } \\
\text { sign, it is graphic- } \\
\text { based rather than } \\
\text { text which supports } \\
\text { user diversity. }\end{array}$} \\
\hline $\begin{array}{l}\text { 1- To what degree does the space foster users' attachment to } \\
\text { it while offering opportunities for an intensive human experi- } \\
\text { ence? }\end{array}$ & 2 & & \\
\hline $\begin{array}{l}\text { 2- To what degree does the physical design of space foster the } \\
\text { feeling of comfort and relaxation? }\end{array}$ & 1 & & \\
\hline $\begin{array}{l}\text { 3- To what degree does the space consider the dimensions of } \\
\text { personal space and privacy? }\end{array}$ & 2 & & \\
\hline $\begin{array}{l}\text { 4- To what degree does the space offer the feeling of safety } \\
\text { and security to its users? }\end{array}$ & …............ & & \\
\hline Boundaries & 3 & \multirow{10}{*}{$\begin{array}{l}\text { Insert text that justifies the score. } \\
\text { The architecture and design of } \\
\text { the place inspires attention and } \\
\text { alert rather than comfort, due } \\
\text { to the continuous movement of } \\
\text { people and cars following } \\
\text { the linear arrangement of the } \\
\text { street. In addition, the street } \\
\text { itself has no architectural } \\
\text { character, but gains its value } \\
\text { as a result of the important } \\
\text { landmarks around such as } \\
\text { souq wagif and the active } \\
\text { neighbourhood. } \\
\text { Place attachment is hardly } \\
\text { assessed due to the absence } \\
\text { of the local residents, but the } \\
\text { migrants might have certain } \\
\text { personal attachments. }\end{array}$} & \multirow[b]{2}{*}{ Insert illustration that justifies the score. } \\
\hline Security personnel & $1 \ldots$ & & \\
\hline \multirow{2}{*}{$\begin{array}{l}\text { Security cameras } \\
\text { 5- To what degree is the architectural character of this space } \\
\text { being memorable? }\end{array}$} & $\ldots 1 \ldots$ & & \\
\hline & 1 & & \\
\hline $\begin{array}{l}\text { 6- To what extent do the signs in this space consider different } \\
\text { ethnics? }\end{array}$ & 3 & & \\
\hline 7- To what degree is it easy to navigate in this space? & $3 \ldots$ & & \\
\hline $\begin{array}{l}\text { 8- To what degree could the spatial experience in this space be } \\
\text { described as being interesting? }\end{array}$ & 2 & & \\
\hline $\begin{array}{l}\text { 9- To what degree does the architectural character of this } \\
\text { space reflect the identity of Doha? }\end{array}$ & $2 \ldots$ & & \\
\hline $\begin{array}{l}\text { 10- To what degree could this place be described as a major } \\
\text { attraction in the city? }\end{array}$ & $2 \ldots$ & & \\
\hline Average Score (total scores/12) & 1.9 & & 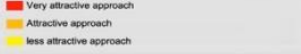 \\
\hline
\end{tabular}

Fig-9: Walking Tour Assessment Tool- Perceptual Aspects. Tool developed by Prof. Salama. Source [32]

Migrant communities occupy the entire site of Najada creating the misconception of a city within a city, where the small city does not reflect the proper identity nor the ambitious urban aspirations of bigger Doha. In terms of accessibility, navigating through the site during non-rush hours seems smooth and easy due to the linear and on-way form of the area. The architecture of the street inspires tension and alert rather than comfort because of the continuous movement of people and vehicles and the tightness of parking spaces. In addition, since foreign male workers dominate the area; it can get slightly uncomfortable for families and women to visit the area.

The site might not be extravagant, but it has characteristics that are unique and distinctive within the context of Doha. Written street signs and instructions in the site are only communicated bilingually, in Arabic and English. Yet, there are several advertisements hanging on the walls that are written in Undo and other native languages of the street users.

\section{Findings: Contemplating Settings}

Three settings are selected to perform contemplating analysis due to their location and the interesting phenomena they showcase within the site. The three settings share the following general characteristics: (i) provision of a constant flow of people; (ii) provision of facilities and functions that are widely favoured; and (iii) establishment of significant focal points in the site. Although the settings have different urban criteria, there are used by the same category of people.

The settings are analysed in terms of people flow, size, time, usage time (number of hours spent by people in the setting), objects and action pattern with regards to concepts of privacy, territoriality, personal space/distance, crowding and density. The methodology used for the analysis are observation as in observing physical behaviour of people and what they are doing in the site; descriptive text; images; videos; note-taking; and annotated diagrams. 


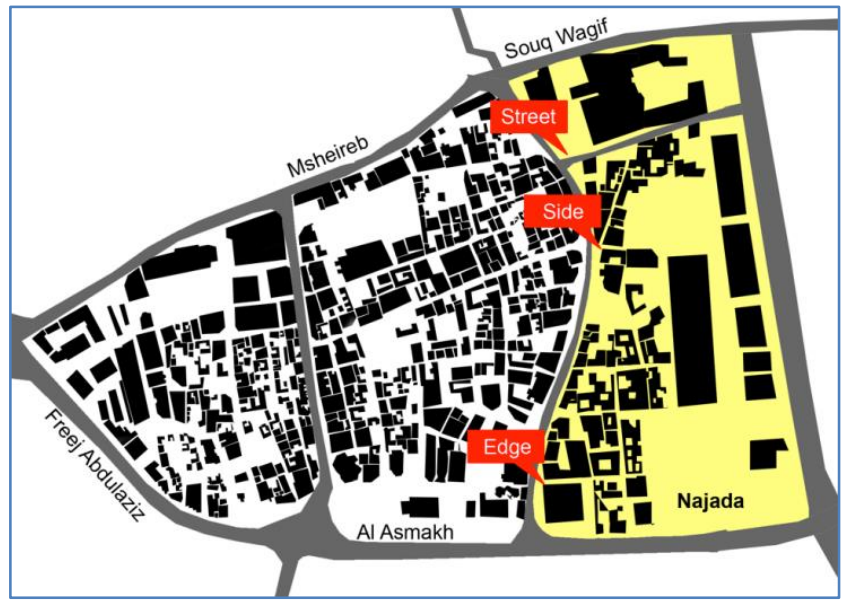

Fig-10: Selected Locations for Contemplating Setting at Najada. Source Authors

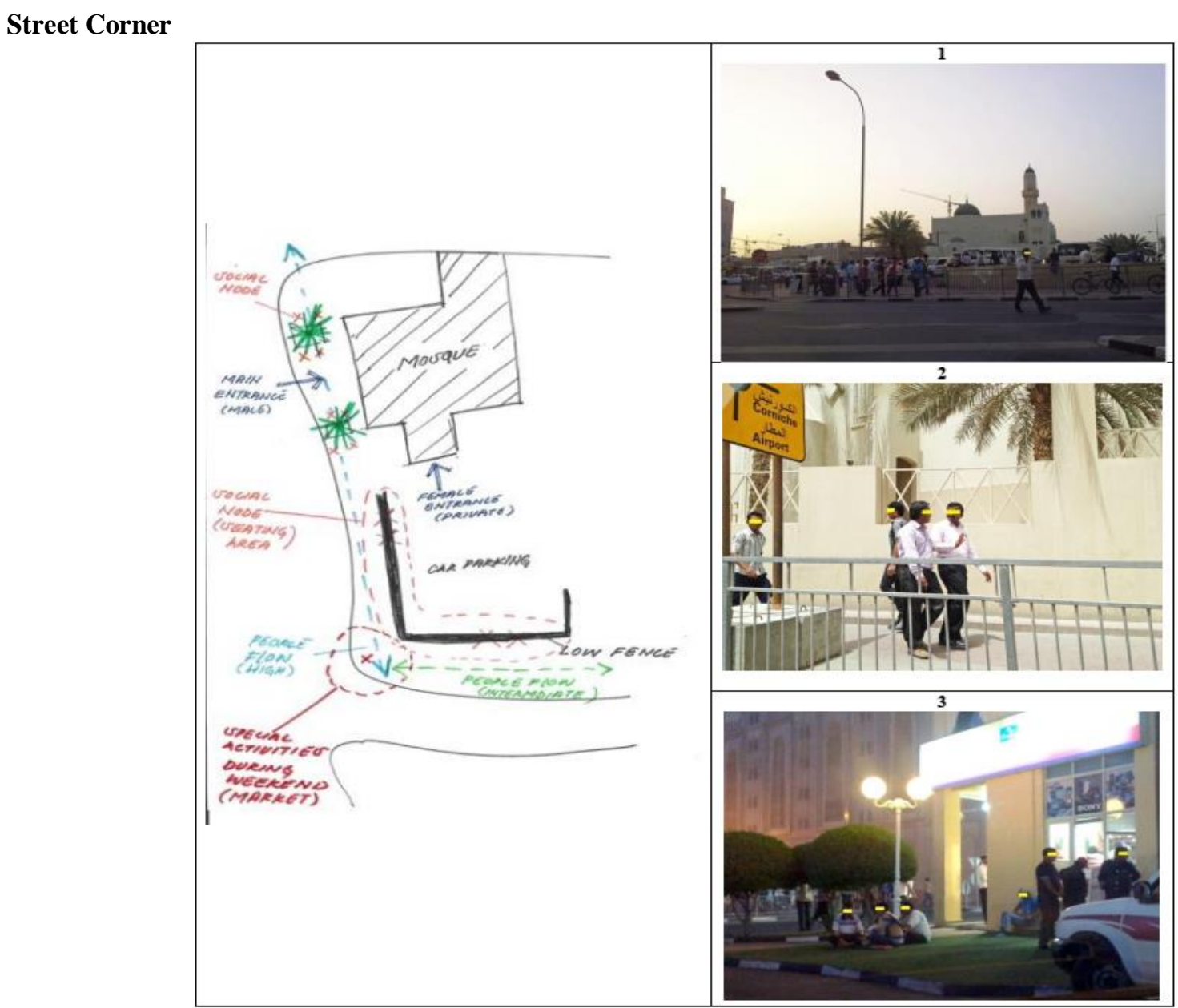

Fig-11: Contemplating Settings 1: Street Corner

The street corner is the first glimpse of the area, appearing as a head start to the journey into Najada. It is the most populous setting in the whole site due to its connectivity to Souq al Najada, Souq Wagif and the main mosque at its center. It also acts as a social node for construction workers as they tend to gather before or after the prayer times - mainly after sunset - or during break times considering the construction works taking place in neighboring sites. The difference in people density between day and night is quite large. There is a lack of urban furniture in the setting, however many pedestrians use the fence for gathering and seating.

During the day, people are often seen walking alone in contrast to evening times when they are mainly 
found in groups. Users in this setting usually prefer dense spaces in contrast to deserted spaces, for several reasons: (i) it gives a feeling of safety; (ii) the scale of the inner corridors is rather narrow and uncomfortable to walk through them. The activities taking place within their respective time frame are repetitive in their nature.

The annotated diagram above (Figure 20) demonstrates the constant line of people flow within the space and the social gathering nodes. The photos in the right highlight the proximity relationship between users, and their preferred personal distance. In the evening, the users are seen more relaxed in their posture and enjoying themselves and their company; whereas in the morning they tend to be more alert and are seen in a hurry most of the time. People from the same ethnic backgrounds tend to sit together, even though the site has its characteristic as a socially diverse area.

\section{Sidewalk Strip}

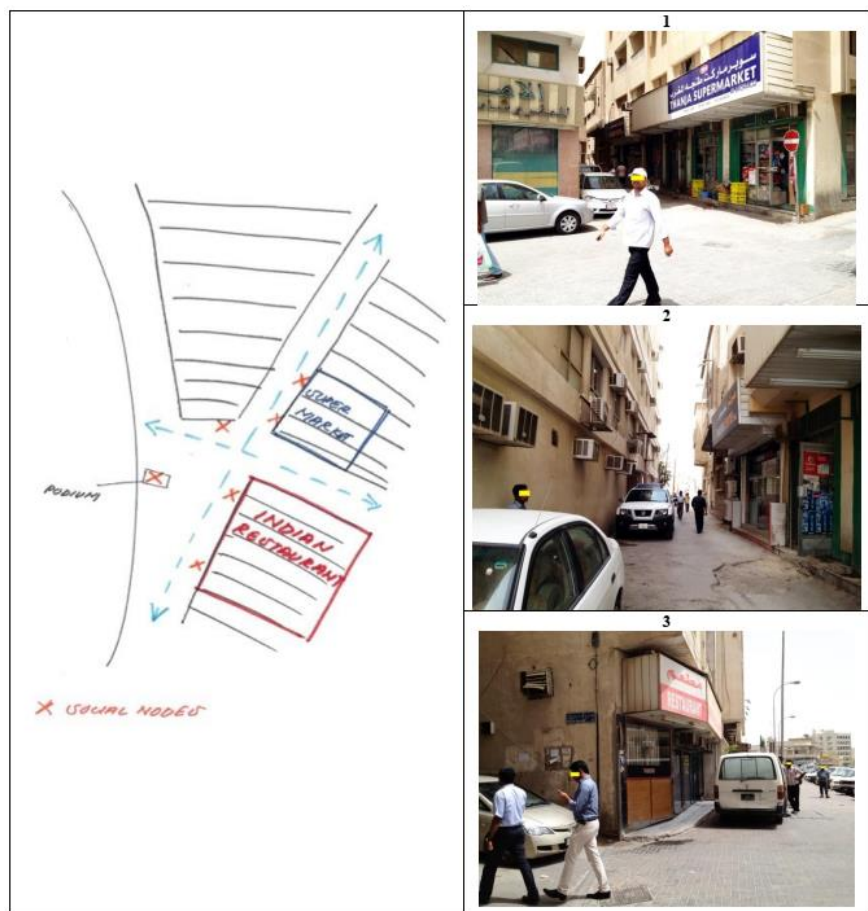

Fig-12: Contemplating Settings 2: Sidewalk Strip
This sidewalk strip is a highly dense space during day and night, weekday and weekend. Various environment-behavior interactions occur in this space although it lacks the appropriate urban furniture and shading devices. One of the reasons owes to the facilities provided, which are in a high demand such as a supermarket and a humble looking Indian restaurant. In an interview with one of the users - Indian by nationality - working for the fit-outs in a neighboring construction site, he stated that "I like to come here every end of the day with my crew to have lunch in the restaurant", with an emphasis on the fact that workers of the supermarket and restaurant are all Indians. The proximity relationship between users is minimal. During the day people are seen walking in solitude, whereas by night they are seen walking in pairs or groups mostly. There is a constant flow of people in this space since it leads to Souq Al Najada through its narrow street as seen in the images above (Figure 22). 


\section{Edge}

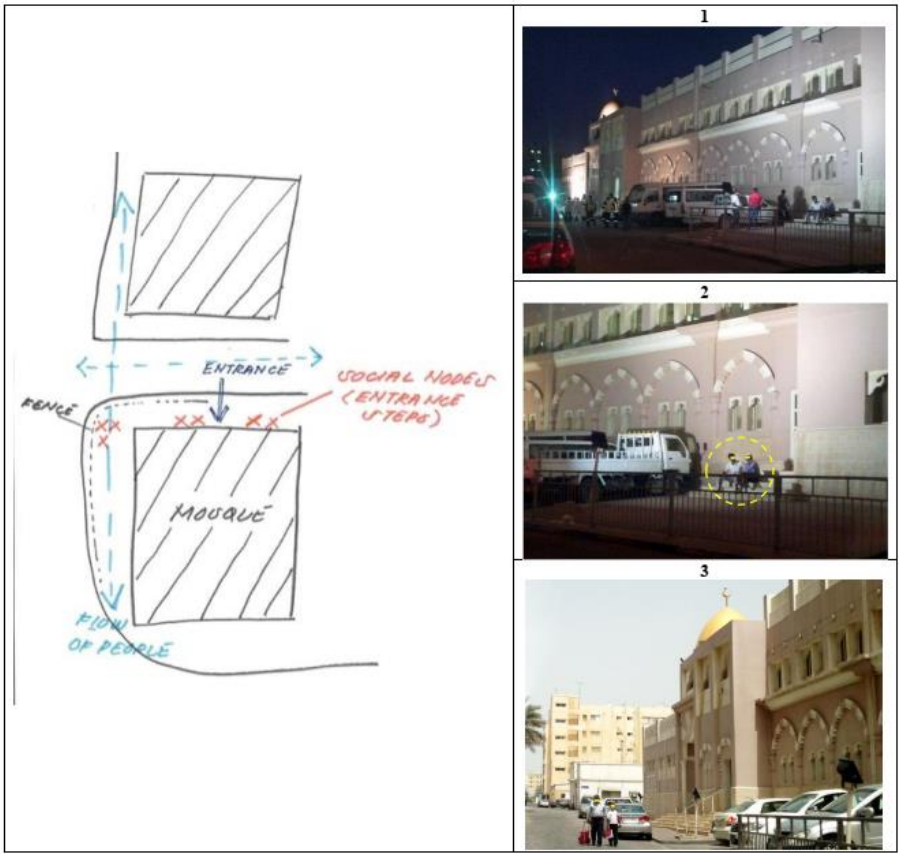

Fig-13: Contemplating Settings 3: Edge

Around the selected edge, there is a vast difference in density of people in day and night. In day, pedestrians are mainly walking in their own, where a huge majority of them are migrant Asian workers. The space is mainly used as a pathway with minimal social gatherings taking place. On the other hand, during the night, there is more variety of activity. Small groups of migrant workers are usually seen sitting on the steps of the mosque's entrance. Users of this space are often seen in a hurry to catch the prayer during prayer times and are seen standing in groups held in conversations in front of the mosque after the prayer is over.

In picture (1) people are seen sitting in the steps of the mosque with a minimal personal distance giving clear indication that the two people seen are acquaintances. Similar phenomenon is exhibited in picture (2), however the two people are setting in front of the mosque's entrance where people are mostly seen in small gathering either talking or waiting for others. Picture (3) is one of the few observed incidents where a parent is accompanying his student son while approaching to either their flat or car.

\section{CONCLUSION AND DISCUSSION}

The following points summarize the outcome of the investigative, reflective observation of the migrant community practice at Al Najada zone in Doha, following the methodological approach of humanbehaviour analysis with a various set of investigative tools:

- $\quad$ People are using the site despite its underdeveloped conditions.

- The area displays different features from those expected or perceived. It lacks the proper fundamentals of a qualitative public space although Najada is widely contemplated as a spacious, crowded district in the heart of the city, therefore assumingly a public space.

- The architectural style is expected to be traditional, specifically low rise, ornamented, leaning toward commercial activities in land use. It turns out to exhibit a mixture of modern and post-modern styles, brought to the city by the initial and rapid urbanization phases of modernity in the 1960s [37].

- Confused architectural styles reflect the degree of interaction between the different ethnological backgrounds. Users of area seem confused, and prefer to interact within their limited social zone.

- Within most of the street shops, interaction between different migrant groups in addition to others is effective. Meanwhile, in the street level, interaction is minimal except for mutual interaction between pedestrians belonging to the same sociocultural background.

- The zone is vibrant with spots of active areas due to the constant flow of people during day and night, weekdays and the most crowded weekends, reflecting a downtown character.

- The area is a high male-dominant area, making it uncomfortable to be used by families, children or female users alone.

- Absence of street furniture and other public facilities restricts social interaction.

- "People set where there are places to set". The statement is invalid, because in Najada, people will set whenever they need to set and use their creativity to adopt the function to the form. Example is setting on steps or fences. 
- People are capable of personalizing spaces in addition to expressing territoriality behavior in spite of the limits of the urban fabric.

- Tracing human-behavior phenomena is a dynamic process since it varies with time, setting, users and investigator themselves.

- Human-behavior studies equip the researcher to perform systematic analysis with several effective tools.

The future of Najada district seemingly is moving toward a full demolish, since the public are reflecting a very dissatisfied attitude toward the overdensity of the migrant communities in one of the most valuable districts of Doha. Remodelling any of the successful neighbouring projects of Souq Wagif or Msheireb could be a reasonable solution. However, for the sake of a distinctive experience, Najada should be treated as a heritage site primarily designed for a mixed-use function and to be accommodated by various social groups including the already residing migrants.

The migrant communities studied in this research are mostly of south-Asian origins. To most of the locals, such communities are well involved in the Qatari society due to the shared commonalities. Interaction between locals and South-Asians has always been friendly. The migrant communities' valuable contribution into developing the country especially their involvement into the economic and commercial sectors suggests that their future in the country is promising. However, they deserve better places of dwell, better homes and better families and yet it is the common responsibility of the whole community to ensure an equitable access to better choices to all members of the society.

\section{ACKNOWLEDGMENTS}

Asmaa Saleh AL-Mohannadi is an architecture engineer by career. She holds Masters of Science in Urban Planning and Design [38], and a bachelor of science Degree in Architecture [32] from Qatar University. She was honoured by HH. Emir of Qatar for Educational Excellence in 2015.

AL-Maha Ahmed AL-Malki is an architecture engineer by career. She holds Masters of Science in Urban Planning and Design [38], and a Bachelor of Science Degree in Architecture [32] from Qatar University.

Raffaello Furlan is an Assistant Professor at the Department of Architecture and Urban Planning (DAUP) at Qatar University. Raffaello Furlan holds Bachelors and Master's Degrees from IUAV University in Venice (Italy), and a $\mathrm{PhD}$ in Architecture from Griffith University in Brisbane (Australia).

The authors would like to acknowledge the support of Qatar University for creating an environment that encourages academic research and unlocks the creative potential of budding researchers.

\section{REFERENCE}

1. AL-Mohannadi, A. S., \& Furlan, R. (2018). The Practice of City Planning and Design in the Gulf Region: The Case of Abu Dhabi, Doha and Manama. Archnet-IJAR: International Journal of Architectural Research, 12(2), 126-145. doi:http://dx.doi.org/10.26687/archnetijar.v12i2.1460

2. Furlan, R., \& Alattar, D. (2017). Urban Regeneration in Qatar: A Comprehensive Planning Strategy for the Transport Oriented Development (TOD) of Al-Waab. Journal of Urban Regeneration and Renewal, 11(2), 168193.

3. QNDF. (2014). Qatar National Development Framework 2032. Retrieved from

4. GSDP, G. S. f. D. P. (2008). Qatar National Vision 2030. Retrieved from Doha, Qatar: http://www.gsdp.gov.qa/portal/page/portal/gsd p_en/knowledge_center/Tab/QNV2030_Englis h_v2.pdf

5. Boussaa, D. (2014). Al Asmakh historic district in Doha, Qatar: from an urban slum to living heritage. Journal of Architectural Conservation, 20(1).

6. Eissa, B., Awwad, R., Awwaad, R., \& Furlan, R. (2015). Neighborhoods and Social Interactions: The Case of Al-Najada Area in Doha. American Journal of Sociological Research, 5(4), 119-133.

7. Furlan, R., Petruccioli, A., \& Jamaleddin, M. (2019). The authenticity of place-making: space and character of the regenerated historic district in Msheireb, Downtown Doha (State of Qatar). International Journal of Architectural Research-ArchNet-IJAR, 13(1), 151*168.

8. Kahraman, G., \& Carter, R. (2019). Adaptation of heritage architecture in $\mathrm{Al}$ Asmakh, Doha: insights into an urban environment of the Gulf. Post-Medieval Archaeology, 54(1).

9. Furlan, R., \& Al-Mohannadi, A. (2018). The Practice of City Planning and Design in the Gulf Region: The Case of Abu Dhabi, Doha and Manama. International Journal of Architectural Research-ArchNet-IJAR, 12(2), 126-145.

10. Furlan, R., \& Faggion, L. (2017). Urban Regeneration of GCC Cities: Preserving the Urban Fabric's Cultural Heritage and Social Complexity. Journal of Historical Archaeology \& Anthropological Sciences, 1(1), 1-16.

11. Khalaf, S. (2006). The evolution of the Gulf city type, oil, and globalization. In J. Fox, N. Sabbah, \& M. A. Mutawa (Eds.), 
Globalization and the Gulf. London: Routledge.

12. Cramer, P. D.-I. J., \& Haase, P. D. C.-P. (2012). Old Doha Preservation: Restoration and Urban Rehabilitation of the Traditional Architecture in Asmakh and NajadaPreliminary Draft Version. Retrieved from Berlin, Germany:

13. Qatar Museums. (2019). Retrieved from http://qm.org.qa/en

14. MDPS, M. o. D. P. a. S. (2010). Analysis of the Results of Population, Housing and Establishments Census 2010. Retrieved from Doha, Qatar:

15. MMUP, M. o. M. a. U. P. (2014). Land Use Maps and General Planning Documents. Doha, Qatar

16. Furlan, R., \& Al-Harami, A. (2019). SocioCultural Factors embedded into the Urban Fabric of Al Zubarah City in Qatar: An Urban Regeneration Vision for Contemporaneous Islamic Urbanism. Journal of Urban Regeneration and Renewal, 12(2), 151-176.

17. Furlan, R., \& Petruccioli, A. (2016). Affordable Housing for Middle Income Expats in Qatar: Strategies for Implementing Livability and Urban Form. International Journal of Architectural Research-ArchNetIJAR, 10(3), 138-151.

18. CGIS-MMUP. (2014). Aerial Photos of Doha. Doha, Qatar

19. Sayigh, A., \& Marafia, H. (1998). Chapter 2Vernacular and contemporary buildings in Qatar. Renewable and Sustainable Energy Reviews, 2(1), 25-37.

20. Furlan, R., \& Almohannadi, M. (2016). Light Rail Transit and Land Use: An Integrated Planning Strategy for Al-Qassar's TOD in Qatar. International Journal of Architectural Research-ArchNet-IJAR, 10(3), 170-192.

21. Furlan, R., \& Fadala, E. A. (2018). Sustainable Neighborhoods in the State of Qatar: Msheireb Downtown Doha. Saudi Journal of Engineering and Technology, 3(7), 446-463.

22. Furlan, R., \& Saeed, M. A. (2018). The urban regeneration of West Bay, business district of Doha (State of Qatar). Journal of Historical Archaeology \& Anthropological Sciences, 3(5), 667-671.

23. Furlan, R., \& Saeed, M. A. (2019). TransitOriented Development in West Bay, Business District of Doha, State of Qatar: A Strategy for Enhancing Liveability and Sense of Place. Journal of Cultural Heritage Management and Sustainable Development, https://doi.org/10.1108/JCHMSD-09-20180062.
24. Furlan, R., \& Saleh, D. (2018). Sustainable Neighborhoods: West Bay, Business District of Doha (State of Qatar). Saudi Journal of Engineering and Technology, 3(8), 529-546.

25. Furlan, R., \& Shubbar, F. (2018). Sustainable Neighborhood in Doha (State of Qatar): A Strategy for Achieving Urban Quality in AlHitmi. Saudi Journal of Engineering and Technology, 3(7), 464-481.

26. Furlan, R., \& Tannous, H. (2018). Livability and Urban Quality of the Souq Waqif in Doha (State of Qatar). Saudi Journal of Engineering and Technology, 3(6), 368-387.

27. Furlan, R., \& Wadi, R. (2017). The Quality of Urban Life (QOUL) of New-Salata Neighborhood in Qatar. American Journal of Sociological Research, 7(1), 14-22.

28. Jaidah, I. M., \& Bourennane, M. (2009). The history of Qatari architecture from 1800 to 1950 (1 ed.). Milano: Skira Editore

29. MDPS, M. o. D. P. a. S. (2016). Analysis of the Results of Population, Housing and Establishments Census 2015. Retrieved from Doha, Qatar:

30. HRW. (2012). Building a Better World Cup: Protecting Migrant Workers in Qatar Ahead of FIFA 2022. Retrieved from

31. Furlan, R., \& ElGihani, H. (2018). Post 2022 FIFA World Cup in the State Qatar: Urban Regeneration Strategies for Doha'. Journal of Urban Regeneration and Renewal, 11(4), 355370.

32. Salama, A. M., Azzali, S., \& Wiedmann, F. (2017). The everyday urban environment of migrant labourers in Gulf Cities: the case of the old centre of Doha, Qata. City, Territory and Architecture, 4(5).

33. Salama, A. M. (2006). A Lifestyle Theories Approach for Affordable Housing Research in Saudi Arabia. Emirates Journal for Engineering Research, 11(1), 67-76.

34. Geertz, C. (1973). The Interpretation of Cultures. New York: Basic Books, Inc., Publishers.

35. Yengoyan, A. A. (2009). Clifford Geertz, Cultural Portraits, and Southeast Asia. The Journal of Asian Studies, 68(4), 1215-1230.

36. Croissant, A., \& Trinn, C. (2009). Culture, Identity and Conflict in Asia and Southeast Asia. ASIEN, 110.

37. Fox, J., Sabbah, N. M., \& Mutawa, M. A. (2006). Globalization and the Gulf. London Routledge.

38. Furlan, R., Zaina, S., \& Zaina, S. (2016). Urban Planning in Qatar: Strategies and Vision for the Development of Transit Villages in Doha. Australian Planner, 53(4), 286-301. 